\title{
NOTICIAS SOBRE LAS OBRAS REALIZADAS POR EL PLATERO FRANCISCO DE ALFARO EN SAN MARCOS DE JEREZ
}

\author{
POR PILAR NIEVA SOTO
}

La iglesia de San Marcos es, junto con las otras tres dedicadas a los Evangelistas, una de las más antiguas de Jerez, puesto que como ellas fue fundada por Alfonso X el Sabio sobre una primitiva mezquita islámica cuando hizo el repartimiento de la ciudad en el siglo XIII.

Como pusimos de manifiesto en nuestra tesis doctoral dedicada a la platería de Jerez, San Marcos es la única entre las iglesias jerezanas en la que han quedado inventarios de bienes anteriores al siglo XVIII —uno que comienza en 1599 y acaba en 1646 y otro que se inicia este mismo año terminando en 1687- y una de las que conserva libros de visitas y cuentas de fábrica más antiguos comenzando el primero en 1641 .

Precisamente en los inventarios citados hallamos una interesante noticia en relación con el encargo de varias obras al famoso platero del siglo XVI Francisco de Alfaro $^{2}$ cuyo interés se acrecienta al haberse conservado en la iglesia dos de las tres piezas que hizo en el año 1596.

1. NIEVA SOTO, Pilar: La platería del siglo XVIII Jerez de la Frontera, Madrid 1992, Universidad Complutense, Madrid 1992, I, 200.

2. Sobre Francisco de Alfaro se han publicado noticias varias desde fines del siglo pasado entre las que destacamos las siguientes por orden cronológico de aparición: GESTOSO PÉREZ, José, Sevilla Monumental y artística, tomo II, Sevilla 1890; IDEM, Ensayo de un diccionario de los artífices que florecieron en Sevilla desde el siglo XIII al XVIII inclusive, tomo II, Sevilla 1900; HERNÁNDEZ DÍAZ, J.; SANCHO CORBACHO, A. y COLLANTES DE TERÁN, F., Catálogo arqueológico y artístico de la provincia de Sevilla, tomo II, Sevilla 1943; SANCHO CORBACHO, Antonio, Orfebrería sevillana (siglos XIV al XVIII), Sevilla 1970; SANZ SERRANO, M Jesús, La orfebrería sevillana del barroco, Sevilla 1976; MORALES, A.; SANZ, M. J.; SERRERA, J. M. y VALDÍVIESO, E., Guía artística de Sevilla y su provincia, Sevilla 1981; $2^{\mathrm{a}}$ edic. 1989;MORALES, A.; OLIVER, A.; PLEGUEZUELO, A.; SANZ, M. J.; SERRERA, J. M. y VALDEVIESO, E., Inventario artístico de Sevilla y su provincia, tomo II, Madrid 1985; PALOMERO PARAMO, Jesús María, La platería en la catedral de Sevilla, Sevilla 1985; CRUZ VALDOVINOS, José Manuel, Cinco siglos de platería sevillana, Madrid 1992; GARCÍA LEÓN, G. en Luis Vélez de Guevara y su época, Écija 1994. 
Según ha podido documentar Mercedes Valverde, Francisco de Alfaro debió de nacer hacia 1548, o poco antes, en Córdoba puesto que su padre, el famoso artífice Diego de Alfaro, probablemente también de origen cordobés pues sus padres lo eran, casó allí en 1546 con la cordobesa María Hernández tras abandonar Valladolid donde se hallaba avecindado en enero de 1543 , fecha en la que envió una carta al obispo de Córdoba don Leopoldo de Austria para quien trabajaría unos años más tarde ${ }^{3}$.

Observa Mercedes Valverde que Francisco comenzaría a ayudar a su padre desde muy joven, por un lado porque firmó como testigo (junto a otros tres plateros) en la escritura otorgada por su padre el 28 de febrero de 1571 para arrendar una tienda en la calle de la Platería de Córdoba y por otro porque se ocupó de concluir y cobrar algunas de las obras que estaban iniciadas cuando Diego murió prematuramente en 1573. Asimismo fue designado tutor de los tres hijos menores que había tenido Diego de Alfaro en su segundo matrimonio. Tras el fallecimiento de su padre se estableció en Sevilla pero a pesar de ello recibió algún encargo importante de la catedral de Córdoba ${ }^{4}$.

Desde 1572 Francisco de Alfaro trabajaba para la parroquial de San Juan Bautista de Marchena, donde realizó obras durante veinticinco años. En los años siguientes se ocupó de hacer las custodias de asiento de Santa Ana de Triana, San Juan de Marchena, Santa Cruz de Écija y Santa María de Carmona, además de otras obras de menor envergadura para éstas y otras iglesias sevillanas, posiblemente iniciadas también por Diego años antes.

En 1593 fue nombrado platero de la catedral de Sevilla siéndole encargadas desde entonces obras de la importancia del sagrario del altar mayor (1593), la pareja de atriles (1594) y los doce relicarios (1596) —conservadas todas ellas en el templo hispalenseal tiempo que la restauración de las cruces de cristal de roca y de la metropolitana comprada a Merino. Su cargo de platero de la catedral no le impidió cumplir con los encargos de otras iglesias, por lo que en este año de 1596 además de hacer una cruz para San Juan de Marchena (directamente inspirada en la catedralicia de Merino) realizó tres obras para San Marcos de Jerez como enseguida comentaremos.

En 1597 hizo los atriles de San Juan de Marchena (similares a los de la catedral) y la peana de la custodia catedralicia realizada por Juan de Arfe. En los últimos años del siglo XVI haría una custodia de asiento para la villa de Montilla que, como ha podido documentar Blanca Santamarina, se trata de la conservada en la catedral de Sevilla conocida como custodia chica ${ }^{5}$. Por último en 1600 marchó a Toledo donde permaneció hasta su muerte en 1610 como tesorero del cardenal Sandoval y Rojas.

Tras estos breves datos biográficos pasamos ya a hablar de las piezas que la iglesia de San Marcos de Jerez encargó a Francisco de Alfaro y que en todos los casos datan de 1596. La primera de ellas es una crismera (Fig. 1) para el bautismo

3. VALVERDE, Mercedes y RODRÍGUEZ Mª José: Platería cordobesa, Córdoba 1994, 183-85.

4. Ibidem, 184-85.

5. SANTAMARINA NOVILLO, Blanca: Parroquia, convento y catedral: Fortuna de una custodia de Francisco de Alfaro (de próxima aparición en "Archivo Español de Arte"). 
con cruz central y ramales laterales sustentando los vasos del crisma y óleo de los catecúmenos, que según consta en el inventario de $1599 / 1646^{6}$ se hizo en el año de 1596 con la plata de otra vieja (que pesó 3 marcos y medio incluyendo el óleo) y más dinero que se dio al platero Francisco de Alfaro. Imaginamos por la descripción del inventario que las crismeras viejas tenían una forma semejante a las que se encargaron a Alfaro lo cual no es sorprendente si tenemos en cuenta que este modelo fue creación de la platería sevillana ${ }^{7}$ y que tuvo una enorme difusión por toda la diócesis ${ }^{8}$, llegando incluso hasta Hispanoamérica como demuestran las mejicanas conservadas en la iglesia de San Miguel de Jerez ${ }^{9}$.

En el siguiente inventario de San Marcos, que abarca desde 1646 hasta 1687, se describen así las crismeras tras copiar textualmente el inventario anterior: "ytem unas crismeras de plata dorada en una cruz con su pie a manera de caliz, la mançana de maçoneria con sus bassas y tapadera en que esta la crisma y oleo que pessan tres marcos y medio estando con su oleo como parece de la raçon del protocolo viejo las quales tienen una crucetica y un cruxifijo (sic) de bulto". No advirtió el escribano que el peso correspondía a las crismeras anteriores a 1596 cuya plata fue aprovechada por Alfaro al hacer las suyas más pesadas (puesto que recibió más dinero aunque no se precisa la cantidad).

La pieza era como hemos dicho sobredorada en origen, pero actualmente apenas quedan restos de dorado; mide $38 \mathrm{~cm}$. de altura, $17 \mathrm{~cm}$. de anchura, $13 \mathrm{~cm}$. de diámetro de pie; y $4,4 \mathrm{~cm}$. de diámetro la boca de los vasos. Ha perdido el remate del recipiente destinado al crisma y el pie no es original. Efectivamente según consta en el libro de visitas correspondiente a los años 1679-87 se anota en una "quenta por comicion" que se toma al mayordomo y que parece corresponder a 1681 que se aderezaron las crismeras y se les hizo un pie nuevo lo que tuvo un costo de 30 reales.

6. Inventario y memoria de la plata, joyas y hornamentos y otras cosas que la iglesia de señor Sant Marcos tiene para su servicio y ornamentos del culto divino el qual se hizo y renovo por diziembre de mill y quinientos y noventa y nueve. Este documento y el resto de los correspondientes a la iglesia de San Marcos se encuentran depositados actualmente en el Archivo Diocesano de Jerez.

7. CRUZ VALDOVINOS, José Manuel, Cinco siglos de platería sevillana, Madrid 1992, 12.

8. Pueden verse ejemplares de crismeras de este tipo en $\mathbf{M}^{\mathbf{a}}$. J. SANZ SERRANO, La orfebrería sevillana del barroco, Sevilla 1976 y M². C. HEREDIA MORENO, La orfebrería en la provincia de Huelva, Huelva 1980. Obsérvese que las de la parroquia onubense de San Miguel en Cumbres Mayores (I, 132 y fig. 122) que esta autora considera de primera mitad del siglo XVII, son extraordinariamente parecidas a las de Jerez salvo en la cruz que tiene los brazos planos (como la de Marchena) por lo que no descartamos que fueran también obra de Francisco de Alfaro teniendo además en cuenta que en la misma parroquia se conserva otra crismera (I, 95 y fig. 56) que Heredia relaciona con la de Santa María de las Nieves en la Algaba, ejecutada por Francisco de Alfaro en 1581. Por nuestra parte conocemos en Jerez los siguientes ejemplares de crismeras de este tipo: en la iglesia de Santiago unas del siglo XVI; en la de San Marcos las de fines del XVI que ahora estudiamos; en la de San Juan de los Caballeros unas de fines del XVI o comienzos del XVIII; en San Mateo y en San Lucas dos de la segunda mitad del siglo XVIII y en la Catedral otras de comienzos del siglo XIX. Ninguna de ellas lleva marca pero lo más probable es que se hicieran en el propio Jerez.

9. NIEVA SOTO, Pilar: Plata y plateros en la iglesia de San Miguel de Jerez, Jerez1988, 114-116. 
Por su parte el noveno mandato de la visita de 1687 ordenaba que "lás olieras se doren por de dentro para que los santos oleos toquen siempre en lo dorado"; no obstante no parece que tuviera efectividad puesto en el tercer mándato de la visita

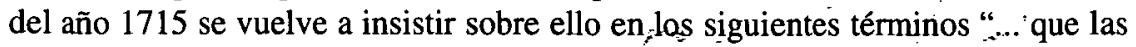
tapas de las chrismeras de los santtos oleos chrisma de cattecumenos y enfermos se doren por denttro"; asimismo se hacía referencia al lugaŕ en el que debían guardarse éstas “... y dichas crismeras se guarden en la ttaquilla que esta del lado de el altar comulgattorio destinado para este efectto y no en la capilla del bauptismo y se enmiende el rotulo que tiene en la partte superior que diga olea sacra".

Las crismeras constan de una cruz latina de brazos cilíndricos terminados en adorno de pirámide con bola y Crucificado de tres clavos con las rodillas giradas hacia su izquierda y la cabeza levantada hacia la derecha; a los pies de la cruz se disponen dos trazos laterales que sustentan vasos cilíndricos recorridos por gallones pareados en su parte inferior y cubiertos con tapaderas de perfil convexo que en un caso remata en $\mathrm{O}$ y en el otro se ha perdido.

Al mismo tiempo que las crismeras destinadas al bautismo, Alfaro recibió el encargo de realizar otra para el óleo de enfermos que desgraciadamente no ha llegado a nuestros días. Como en el caso anterior esta obra se realizó aprovechando la plata de una ampolleta antigua (que con el óleo pesaba cinco onzas y dos reales) y algo más de dinero que se le entregó y que tampoco se anota. De la pieza que realizó Alfaro sólo sabemos que tenía asa y cruz alta y lisa como remate de la tapa. Aparte de estos datos en el inventario de 1599 a 1646 únicamente se indica que se guardaba en el sagrario. Nada nuevo se añade en el siguiente inventario, pero de los libros de visitas y cuentas de fábrica de la iglesia se pueden extraer las siguientes noticias:

En la visita del 15 de abril de 1676 consta que se gastaron veinte reales por el “... aderezo que se hizo en el relicario de sacramenttar los enfermos" y que debió correr a cargo de Juan Díaz de Mendoza que era el platero que trabajaba en la iglesia en esos años. En la visita del 10 de octubre de 1692 se anota el gasto de 22 reales y medio que costó dorar la "abujeta del santo oleo" si bien también podría tratarse de la pajuela de las crismeras del bautismo. En el tercer mandato de la visita realizada el 16 de mayo de 1698 hallamos una noticia referente a la manera en la que debía llevarse el óleo a los enfermos "... siempre que fuese nesesario ministrar el santo oleo despues de la sagrada comunion se lleve en un vasito pequeño pendiente de un cordon al cuello".

Encontramos aquí una peculiaridad de las piezas jerezanas destinadas al Viático: que se llevaban colgando de un cordón para trasportarlas mejor desde la iglesia a casa del enfermo. No obstante no tenemos noticia de que en este momento en San Marcos se hiciera una crismera para enfermos con estas características, por lo que debieron mantener la de Alfaro todavía unos años hasta que probablemente su deterioro o quizá precisamente la necesidad de llevarla colgada obligó a fundirla como enseguida veremos. Así en unas cuentas tomadas al mayordomo de fábrica 
a fin del año 1727 y que comprendían las partidas de los dos últimos años se hace constar que se gastaron 153 reales y 15 maravedís en hacer "la ampolleta nueba del oleo ademas de la viexa que se dio en cambio y fueron los veinte $i$ un rreales y medio de plata de mas peso que la viexa y los sesenta rreales de plata de la hechura, consto de apuntazion del mayordomo en su libro de maiordomia" . Tampoco esta crismera realizada con la plata de la de Alfaro se ha conservado pues en la visita celebrada el 24 de noviembre de 1784 se anota la hechura de una nueva para el santo óleo que iría dorada sólo por dentro.

La tercera pieza encargada por la fábrica de San Marcos a Francisco de Alfaro fue un copón (Figs. 2-4) que se conserva en la iglesia aunque con algunas transformaciones posteriores. El inventario antiguo indica que se hizo de una custodia vieja que pesaba casi seis marcos y tenía el vástago de cristal con una manzana dorada en medio. Con la plata que se consumió "y ottra que se puso hizo el dicho Alffaro un relicario dorado todo con una cruz dorada alta llana y el dicho relicario tiene quattro quadrados blancos con los versos del sacramento".

Como ocurre en el caso de las otras piezas este texto y el correspondiente a la descripción de las piezas antiguas consumidas se copia íntegramente en el inventario levantado en 1646, si bien ahora se añade algún dato sobre el copón del citado artífice y el sol que se le acababa de añadir para utilizarlo también como custodia portátil: "... se hizo de nuevo todo con una cruz alta dorada llana y con la copa redonda labrada y en la bola del pie tiene quatro quadrados blancos con los verssos del Santisimo Sacramento con un medio sol dorado que pesso sinco marcos y dos onzas que se pone por inventario".

Curiosamente la partida relativa a la hechura del sol aparece repetida en la visita del 28 de mayo de 1646 y en la del 7 de mayo del año siguiente, con la única diferencia de que en esta última la cifra anotada es de 275 reales en lugar de los 270 que constan en la primera. La posible explicación a la doble anotación de esta partida es que - por razones que ignoramos - no fuera abonada en 1646 y se pagara en la siguiente visita.

Según se indica en las partidas aludidas “... para poner un sol en la custodia se saco licencia de el señor provisor para que esta fabrica aiudase con ducientos reales de plata que con el ttrueque montan ducientos y setenta reales de vellon que da pagados a don Diego Adame como consto de resivo y el mandamiento de el señor provisor despachado en dos de setienbre de quarenta y sinco años que se le descargan"

Ignoramos si el viril nuevo que aparece anotado en la visita del 20 de noviembre de 1695 era para este sol o para otra custodia, como también si la cruz que se mandaba hacer parałponer "sobre la pixide del sagrario del altar mayor" en la visita del 19 de noviembre de 1691 y que se hizo "para el copon grande" por 60 reales en 1698 y se doró por 45 en este mismo año, iban destinados al copón que en 1596 había ejecutado Alfaro.

Para terminar con las noticias que aporta la documentación mencionaremos que en la visita del 16 de mayo de 1718 se gastaron 7 reales y $1 / 2$ en componer el viril de la custodia (que como en el caso anterior puede o no ser el que ahora estudiamos) 
mientras que en la visita celebrada el 20 de junio de 1778 se pagaron 75 reales por el dorado de un copón, 127 por el de otro (y el pie del altar mayor) y 100 por dorar el viril. Todos estos redorados los hizo el artífice Juan de Medina que había aprendido el arte con el famoso jerezano Francisco Montenegro.

El copón es de plata sobredorada y en su color en los recuadros del nudo; actualmente tiene el vástago poco firme; mide $38 \mathrm{~cm}$. de altura con tapa; $24,5 \mathrm{~cm}$. sin ella; y $69 \mathrm{~cm}$. con el sol; $32 \mathrm{~cm}$. de anchura máxima el sol; $16 \mathrm{~cm}$. de diámetro el cerco exterior; $13 \mathrm{~cm}$. de diámetro el viril; $18 \mathrm{~cm}$. el pie; y $14 \mathrm{~cm}$. de diámetro de boca. En las cuatro caras del nudo lleva grabados en latín los siguientes versos ${ }^{10}$ :

\section{TANTV/M ERG/O SACR/AMEN/TVM; EN SV/PRE/ME NO/CTE S/ENE; O SAC/RVM C/ONVI/VIVM /IN QVO/XPS; CIBV/M TVR/BE DVO /DENE /SEDAT.}

Copa de tipo hemisférico recorrida en su parte inferior por grupos de tres gallones alternando con costilla plana y en la parte superior por espejos ovales y puntas de diamante. Tapa de base plana y perfil convexo adornada con triples gallones y espejos rectangulares y rematada en gollete cilíndrico sobre el que reposa una cruz de brazos diédricos acabados en bola. En el astil varios filetes de diverso diámetro anteceden al nudo de paralelepípedo, con contrafuertes estriados en cada cara y recuadros terminados en frontón con los versos citados grabados. Por debajo quedan un pequeño jarrón con asillas perladas y espejos y un gollete cilíndrico. El pie es de planta cuadrada con cuatro lóbulos salientes adornados con los Evangelistas sentados, con libros y con su símbolo y con cabeza de querubín en los ángulos.

El sol tiene un alargado vástago troncocónico con asillas en la parte inferior y consta de un cerco de treinta rayos, alternando lisos con flameados, y remata en cruz latina de brazos diédricos con terminación de bola. El viril tiene marco liso y está formado por 58 rayos combinando los lisos con los que tienen forma de llama.

Las crismeras y el copón de San Marcos de Jerez presentan obvios paralelismos en estructura y adorno al tiempo que se asemejan bastante a algunas de las obras que Alfaro realizó entre 1585/89 para San Juan de Marchena. Así por ejemplo las dos obras jerezanas coinciden en la forma de iniciar el astil, en el cuerpo de jarrón -más desarrollado en el caso de las crismeras- con asillas perladas en el toro, en el

10. La transcripción correcta de los versos en latín y su traducción al castellano es la siguiente:

TANTVM ERGO SACRAMENTVM (Tan grande Sacramento pues. ..)

IN SVPREMAE NOCTE COENAE (En la noche de la Ultima Cena...)

O SACRVM CONVIVIUM IN QVO XPS (;Oh! sagrado convite en el que Cristo)

CIBVUM TVUBAE DVO DENAE SE DAT (Se da como alimento al grupo de los Doce)

Los versos $1^{\circ}, 3^{\circ}$ y $4^{\circ}$ pertenecen al Pange lingua, himno eucarístico compuesto por Santo Tomás de Aquino y propio de la procesión del Corpus, mientras que el $2^{\circ}$ es el inicio de la antífona con que concluye el cántico de la procesión del Corpus Christi. 
gollete cilíndrico que se dispone por debajo y seguramente también coincidieron en la forma del pie, puesto que el de las crismeras de Marchena de 1588 es similar al del copón de Jerez excepto en la iconografía ".

Por su parte las crismeras de Jerez difieren de las de Marchena en el tipo de cruz que en el primer caso es cilíndrica y en el segundo de brazos planos aunque la terminación de éstos en pirámide y bola es igual en los dos ejemplares. Los Crucificados son muy distintos en ambos pues mientras que el de Jerez no lleva nimbo, levanta la cabeza hacia su derecha y gira las rodillas al lado contrario, el de Marchena cubre su cabeza colgante con un gran nimbo, arquea más los brazos y deja caer las rodillas flexionadas en una posición más frontal.

Exactamente iguales son las dos cartelas que arrancan del pie de la cruz de ambas crismeras para sustentar los recipientes; éstos son en los dos casos cilíndricos, con tapadores bastante planos y van adornados con ces buriladas; difieren en cambio en que los de Jerez llevan gallones pareados en la parte inferior y los de Marchena contrafuertes adosados. Las diferencias son notorias en los dos cuerpos que componen el astil de ambas piezas puesto que mientras en la de Marchena el artífice se inclinó por la utilización de dos formas geométricas muy rectilíneas (el paralelepípedo y el cubo) en la de Jerez prefirió utilizar otras más curvilíneas y suaves al colocar un amplio nudo de jarrón y un gollete cilíndrico, el cual, por otra parte, se halla también presente en otras obras suyas como los blandones de Santa María de Carmona (Sevilla) de 1584 o el cáliz de Marchena del año siguiente.

Por lo que atañe a la forma del nudo del copón de Jerez es casi una réplica del que Alfaro utilizó en tres obras de San Juan de Marchena: el cáliz de 1585, las ya mencionadas crismeras de 1588 y el relicario de custodia de 1589 . No obstante existe una diferencia ornamental entre las obras de esta población sevillana y la de Jerez pues mientras los recuadros de las primeras van ricamente adornados con esmaltes de colores los del copón se han dejado en el color de la plata grabándoles los versos antes citados en latín. Asimismo en la solución dada para el final del astil - colocando un gollete cilíndrico- y en el pie cuadrado con salientes lóbulos convexos en los que sitúa a los Evangelistas coincide totalmente con el cáliz de Marchena ${ }^{12}$.

Como se ha mencionado más arriba en 1645 la fábrica de San Marcos encargó un sol (Fig. 5) para colocarlo sobre la tapa del copón tras quitarle la cruz de remate. De esta forma se pretendía aprovecharlo con una doble función: como copón serviría para reservar las Formas consagradas en el sagrario y como custodia portátil o de manos para exponer al Santísimo en actos litúrgicos solemnes. En nuestra opinión aunque el sol del XVII tiene una hechura correcta, al colocarlo sobre el copón el conjunto no resulta nada armónico, sino más bien bastante desproporcionado.

11. MORALES, A.; OLIVER, A. et alü.: Ob. Cit., II, 30 RAVÉ PRIETO, José Luis: Arte religioso en Marchena. Siglos XV al XIX, Sevilla 1986, n 24 y CRUZ VALDOVINOS, José Manuel: op. cit., 228-229.

12. MORALES, A.; OLIVER, A. et alü.: Ob. Cit., II, 35; RAVÉ PRIETO, José Luis: op. cit., $\mathrm{n}^{\circ} 22$ y CRUZ VALDOVINOS, José Manuel: op. cit. 227-228. 
Para terminar queremos elogiar el talento artístico y la capacidad creadora de Alfaro, pues como ya ha sido puesto de manifiesto en otras ocasiones anticipó algunas de las formas que después serían características del siglo XVII (como el nudo de jarrón con saliente toro o el gollete cilíndrico difíciles de encontrar en otras obras de fines del siglo XVI) y de otro llegó a soluciones distintas en los astiles, brazos de las cruces, modelo de Crucificados, así como en los motivos decorativos ya que a pesar de que los utilizados son los propios del manierismo (espejos ovales y rectangulares, costillas y gallones, puntas de diamante, ces, asillas perladas etc.) en la mano de Alfaro resultan variados y de suma elegancia. Por otra parte, aunque no sea el caso de las obras de Jerez, fue uno de los introductores en Sevilla de los esmaltes opacos. 


\section{APÉNDICE DOCUMENTAL}

Inventario y memoria de la plata, joyas y hornamentos y otras cossas que en la iglesia de señor Sant Marcos tiene para su servicio y ornamentos del culto divino, el qual se hizo y renovo por diziembre de mill y quinientos y noventa y nueve.

(...) Yten unas crismeras de plata doradas en una cruz con su pie a manera de caliz, la mançana de maçoneria con sus bassas y con tapadera en que esta la crisma y oleo, que pesan tres marcos y medio estando con su olio, como parece del protocolo e imbentario viejo y al que le tienen una crucetica y un crucifixo de bulto; año de 96 se hizieron estas nuevas con la plata de ellas y mas dinero que dio a Francisco de Alffaro platero; año de 604 estan las dichas crismeras; año de 613; año 620; año 635; año 637; año 639; año 646.

(...) Yten una ampolla asimismo de plata dorada con tres pesitos y su tapadera sobretapadera con una cruceta llana sin crucifixo que pesa con el olio ymfermos pesa çinco onças y dos reales; en año de 96 se deshizo y de su plata y mas dinero se hizo ottra nueba la que hizo Alffaro con una cruz alta llana encima y su asa; año de 604 esta en la dicha iglesia, digo en el sagrario de ella; año de 613 esta; año de 1620 esta en el sagrario; esta todo año de 635; esta año de 637; año 639; año 646.

(...) Ytem una custodia de plata dorada con la copa sincelalda y con seis pilaricos son los sesados de a laton donde solian estar las vidrieras y con su crucetica y crucifijo de vulto con su pie y el cañon de cristal con una mançana en medio dorada, pesa todo seis marcos menos onça y media; año de 96 se deshizo y desta plata y ottra que se puso hizo el dicho Alffaro un relicario dorado todo con una cruz dorada alta llana y el dicho relicario tiene la copa dorada labrada y en la bola del pie tiene quattro quadrados blancos con los versos del sacramento; año de 604 sirbe el dicho reliquario; año de 613 esta este reliquario; año de 1620 ; esta año de 635; esta año de 637; esta año de 646 con un medio sol dorado que peso 5 marcos y dos onças de plata y se pone por inventario.

Libro de visitas y cuentas de fabrica de la iglesia de San Marcos: 1641-1659

\section{Vísita 28-V-1 646}

$f^{\circ} 128$

Parese que para poner un sol en la custodia se saco lisensia de el señor provisor para que esta fabrica ayudase con dusientos reales de plata que con el trueque montan dusientos y setenta y sinco reales de vellon que da pagados al licenciado don Diego Adame como consto de resivo y del dicho mandamiento de el señor provisor despachado en dos de septienbre de quarenta $v$ sinco años y se le descarga. 


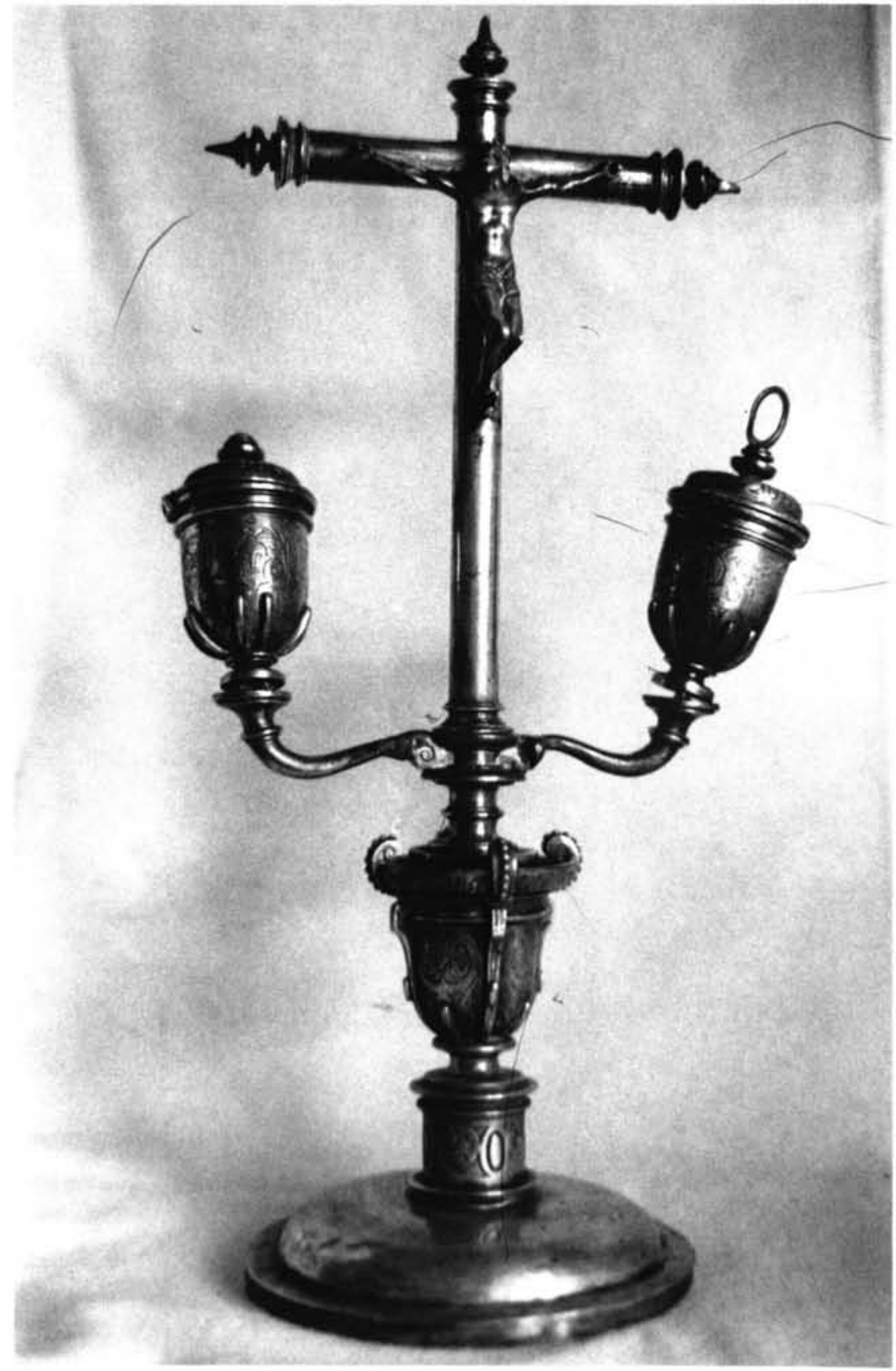

Fig. 1

CRISMERAS: Sevilla, 1596, Francisco de Alfaro. Iglesia de San Marcos de Jerez. 


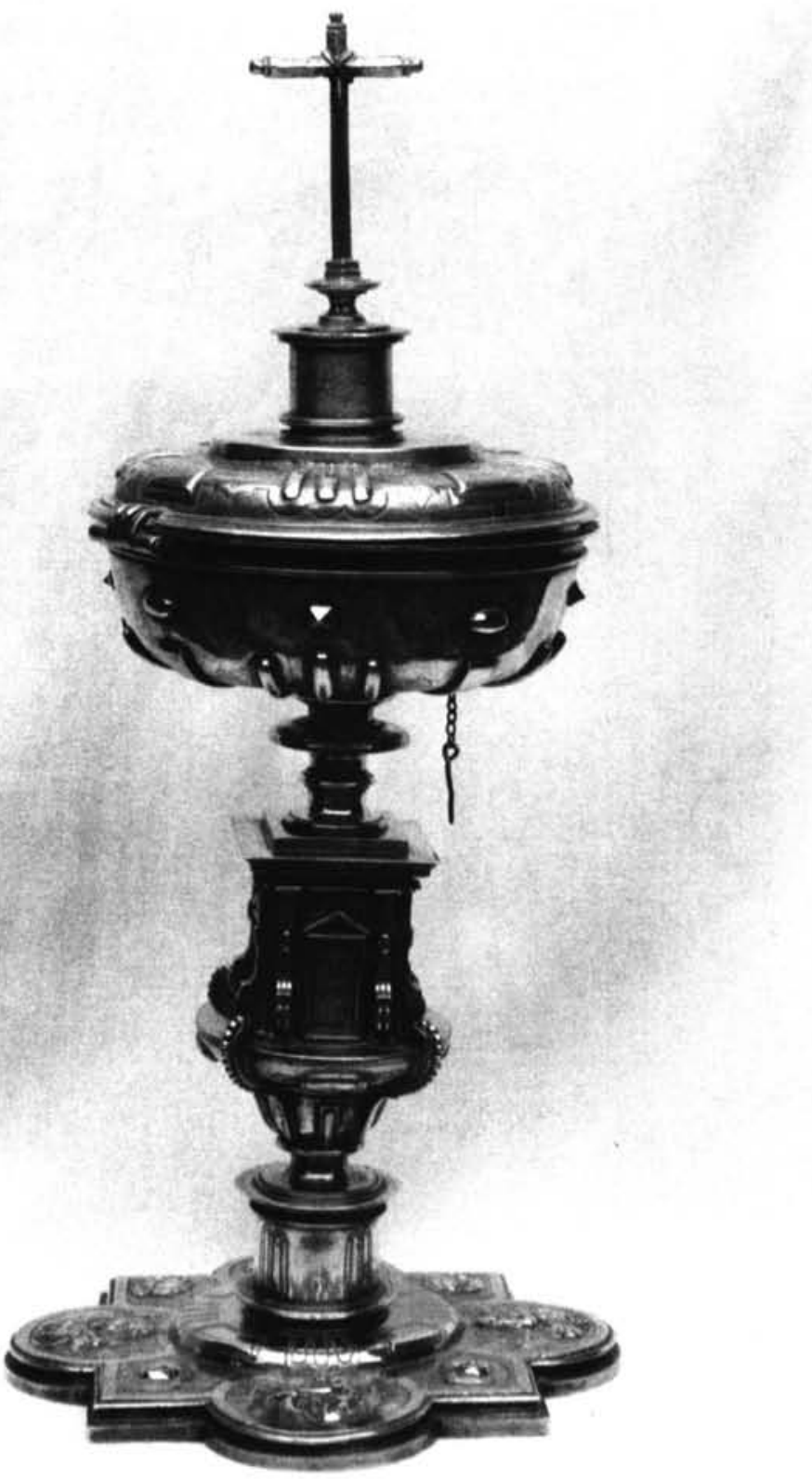

Fig. 2:

COPON: Sevilla, 1596, Francisco de Alfaro. Iglesia de San Marcos de Jerez. 


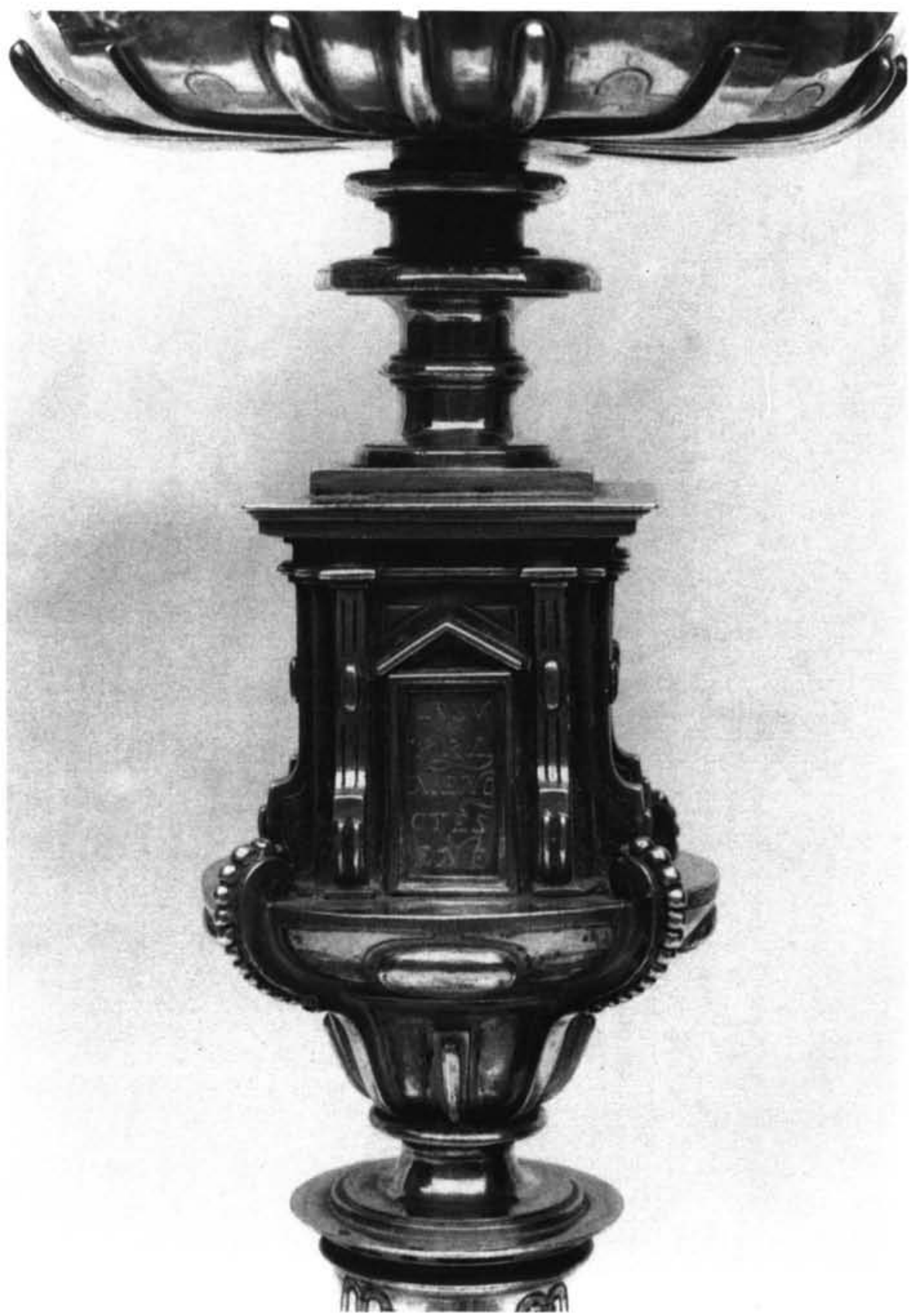

Fig. 3:

Detalle del nudo del copón. 


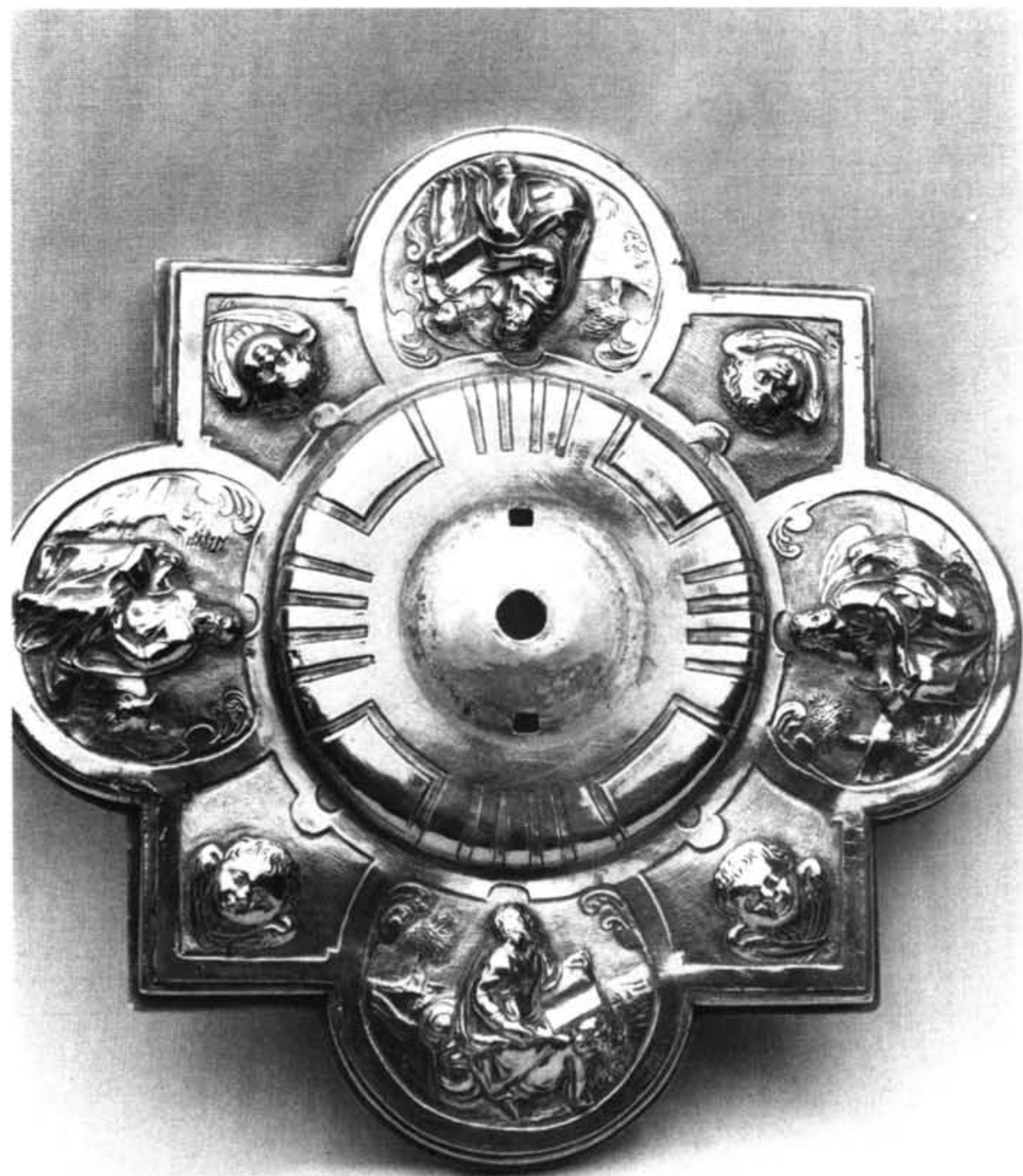

Fig. 4:

Detalle del pie del copón. 


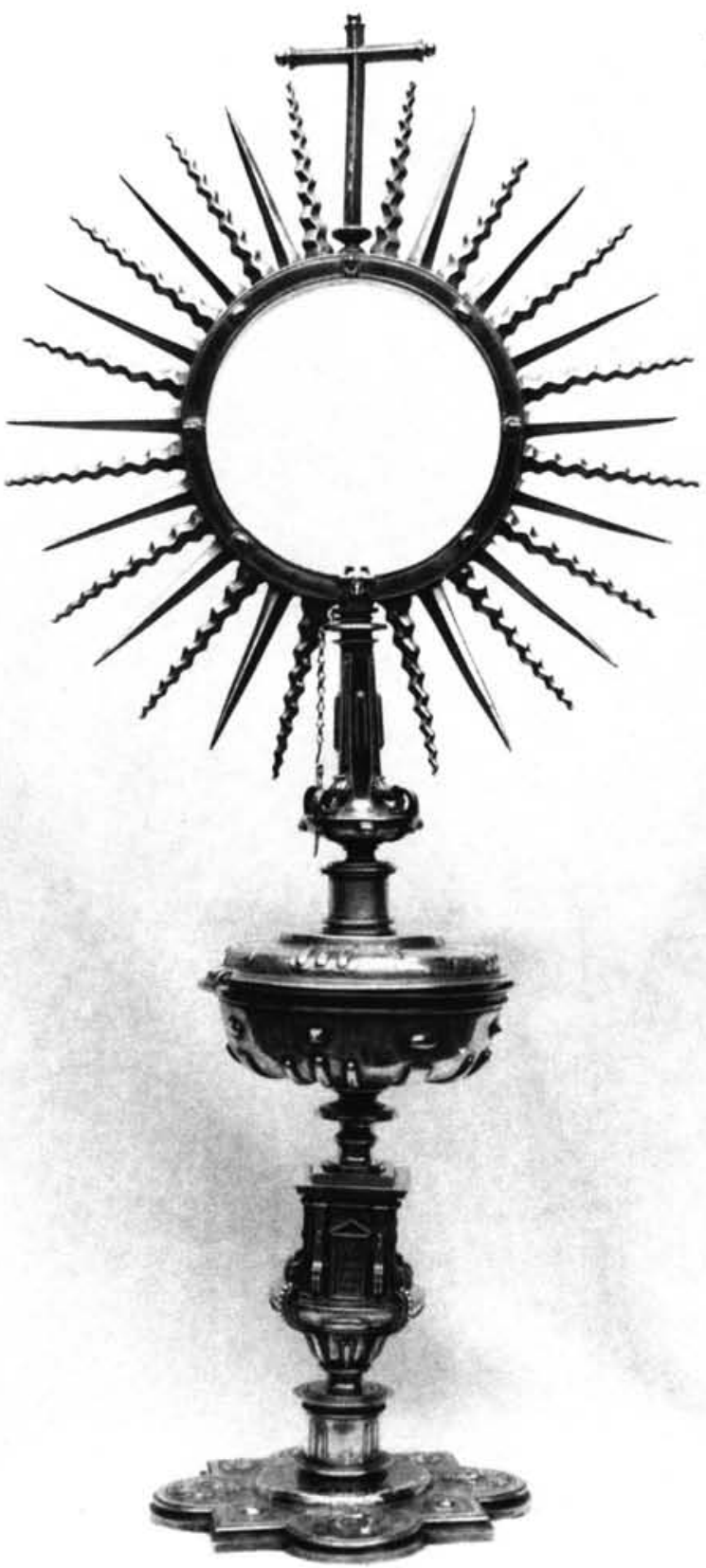

Fig. 5:

COPON de 1596 con el SOL añadido en 1645. Iglesia de San Marcos de Jerez. 